\title{
Promoting Problem Solving Proficiency in First Year Engineering: Compar- ison of Learning Resources
}

\section{Dr. Sarah Jane Grigg, Clemson University}

Dr. Sarah Grigg is a lecturer in General Engineering at Clemson University. Her research focuses on process improvement and error mitigation across various contexts including engineering education, healthcare, and transportation. She received Ph.D., M.S. and B.S. degrees in Industrial Engineering and an MBA from Clemson University.

\section{Dr. Elizabeth Anne Stephan, Clemson University}

Dr. Elizabeth Stephan holds a B.S. and a Ph.D. in Chemical Engineering from the University of Akron. Since 2002, she has been a faculty member in the General Engineering (GE) Program at Clemson University. She has taught, developed and coordinated the first-year curriculum for the GE Program. As the lead author of the Thinking Like an Engineer textbook, currently in the 3rd edition (Stephan et. al., Pearson, copyright 2015), she has been the primary author-team member in charge of the development of the MyEngineeringLab system. She is also the Chief Advisor for SC Alpha Chapter of Tau Beta Pi, The Engineering Honor Society. 


\title{
Promoting Problem Solving Proficiency in First Year Engineering: Comparison of Learning Resources
}

\begin{abstract}
Promoting problem solving skill development is a major focus of our first year engineering courses as problem solving is a critical skill required by practicing engineers. Throughout the semester several different learning resources were utilized to help promote the development of successful problem solving skills, provide feedback on errors, and push students to complete problems in a timely manner. At the end of the term, students and instructors were surveyed about the effectiveness of seven learning resources used in the class. Student and instructor rating were extremely different, with instructors rating in-class learning resources as most effective and students rating on-line learning resources as most effective. Several questions remain, such as whether the delivery method is truly the factor responsible for controlling the students' ability to improve problem solving skills, or if the data is masking an underlying factor.
\end{abstract}

\section{Introduction}

The General Engineering (GE) Program at Clemson University is designed to introduce students to engineering from both an academic and professional prospective. All engineering students at Clemson University begin their academic journey as a General Engineering major and are required to complete a first year curriculum sequence before declaring their intended engineering major. All GE students take a common first-semester course which has three main objectives: (1) to prepare students for the rigor of future engineering classes; (2) to provide students with a solid foundation of basic engineering skills; and (3) to introduce students to the different engineering majors available at Clemson and possible career options. In Fall 2014, the GE program enrolled 1215 new freshman and 177 new transfer students ${ }^{1}$.

Promoting problem solving development in first year engineering courses is critical to ensuring students' transition successfully into upper-division courses and ultimately to a practicing engineer ${ }^{2}$. Innovative approaches to teaching problem solving skills have the potential of appealing to a broader range of students in engineering ${ }^{3}$. "Traditional pedagogical methods, such as requiring students to find information independently, assume a basic competency that not all students possess"3. Thus effective instruction that explicitly addresses problem solving skills relevant to engineering practice has the potential to engage students with diverse experiences and interests. However, as with any new innovation, with change comes the risk of alienating those who prefer the traditional approaches.

The GE Program utilizes a SCALE-UP (Student-Centered Activities for Large-Enrollment Undergraduate Programs) environment, which is a highly collaborative, hands-on classroom format where the primary emphasis is on learning by guided inquiry rather than by traditional lecturing ${ }^{4}$. Learning environments that facilitate student interactions are effective in achieving student-centered and inquiry-based learning, both which are proven approaches for building students' problem solving and laboratory skills ${ }^{5}$. Research on the outcomes of SCALE-UP in engineering and mathematics show students participating in SCALE-UP classrooms exhibited 
higher levels of efficacy with the course material ${ }^{6}$. There is additional evidence of improved academic performance, conceptual understanding, and skills development in students participating in SCALE-UP classrooms compared to traditional lecture-based instruction ${ }^{7}$.

\section{Purpose}

The GE Program is committed to continuously improving our educational practices to ensure students emerge from our program with foundational engineering knowledge and skills required for success in their continuing engineering disciplines and as practicing engineering after graduation. This research describes a preliminary assessment of the learning resources used by Clemson faculty in teaching a first year course which introduces students to the analytical thinking skills required for solving basic engineering problems. All problems used in this class were presented problems ${ }^{8}$ with either a story problem and/or decision-making structure, had a constrained context with pre-defined elements, and could be solved using multiple predictable procedures or algorithms. Some problems had more than one acceptable final recommendation, though in general, students should arrive at the same numerical solutions. For the first year engineering course evaluated in this study, the course content was coordinated across all sections of the course and resources such as lecture slides, worksheets, lab materials, and assignments were made available to all instructors, though the extent of use of specific resources and content delivery techniques were at the discretion of the individual instructor.

At the end of the semester, students and instructors were surveyed about the perceived effectiveness of some learning resources on the impact in aiding students to improve their ability to solve engineering problems. Post-hoc, learning resources were classified according to variation in 1) delivery method, 2) collaboration, 3) feedback response, and 4) performance consequences. Ideally, a full factorial design of experiments would be conducted to obtain a proper analysis of the interaction effects of different combinations of learning resources. The logistics involved in planning, documenting, and executing the numerous combinations of factors in the same semester for our large cohort presents a logistical challenge. Future work plans to include the evaluation of new learning resources designed with the combination of factors that were not met in this study. The end goal is to determine an optimum combination of learning resources to provide the ideal educational experience for the collective group of students.

\section{Methods}

For this investigation, seven of the most frequently utilized learning resources were evaluated. The seven resources are a sample of the total resources available and are in no way an exhaustive list. Four resources were utilized primarily during class time and three were utilized primarily out of class by interacting with MyEngineeringLab (MEL), a web-based homework management system accessed by students as a companion site to the course textbook. MEL is part of the MyLab and Mastering suite of products operated by Pearson Higher Education ${ }^{9}$. The in-class resources included a module worksheet designed to guide students through the lecture including a section with previous content review, a section for basic problems worked in class to check initial concept understanding, and an advanced problem section where constraints and assumptions lead to various acceptable outcomes. Some class days utilized lab activities where 
students conducted mini-experiments with data collection to determine a solution to the advanced problem. The advanced problem was assessed using the PROCESS rubric, developed as a means of measuring the steps required in a problem solving procedure. PROCESS is an acronym for the stages including: Problem definition, Representation of the problem, Organization of information, Calculations, Evaluation of solution, Solution communication, and Self assessment ${ }^{10}$. In addition, in-class review games were played, with students being provided with immediate feedback on the correct answer. Figure 1 shows several of the in-class resources including the module worksheet that featured a hands-on lab with an advanced problem graded using the PROCESS rubric.

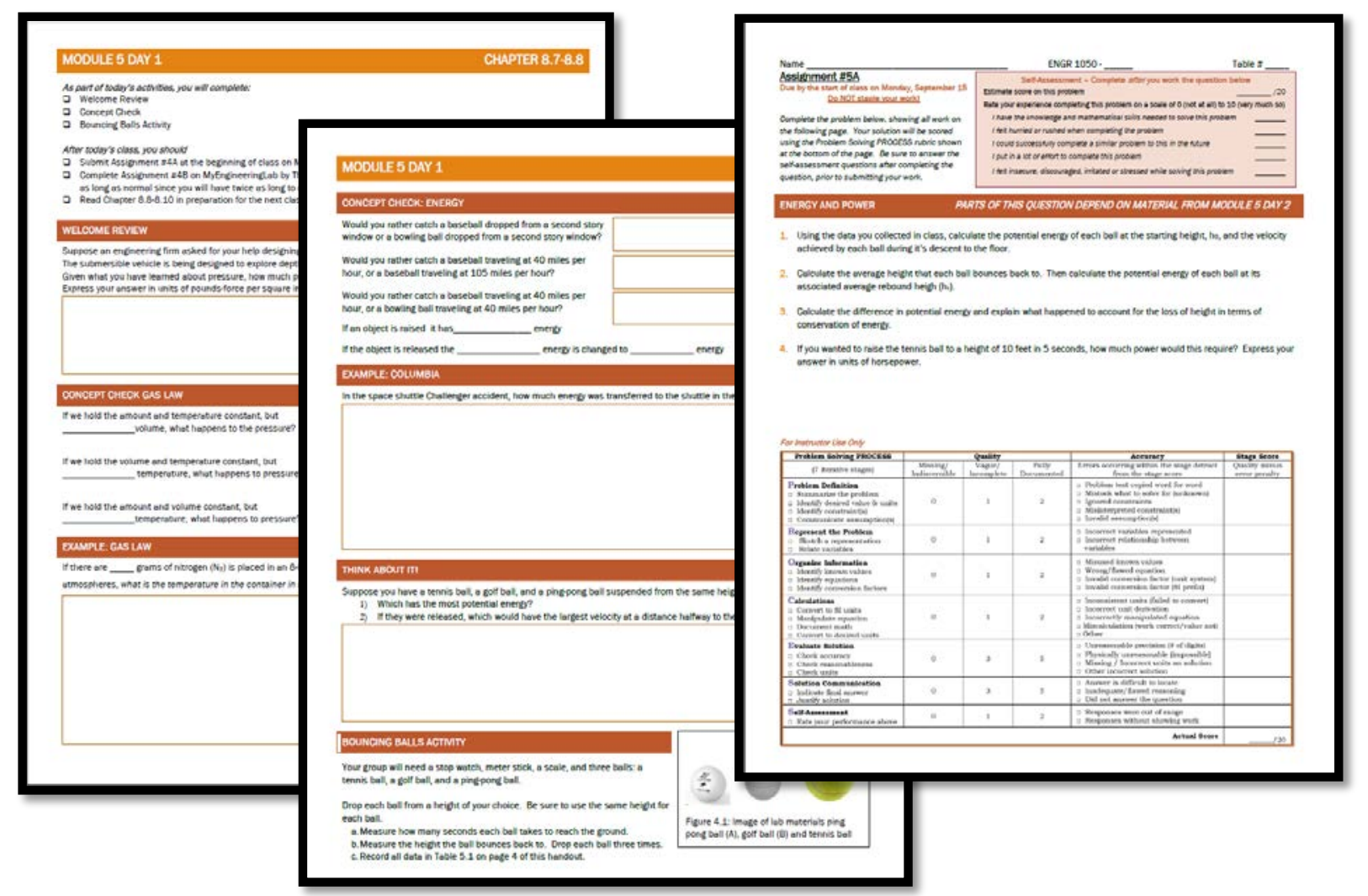

Figure 1: Example of a module activity worksheet with a hands-on lab and PROCESS rubric, shown from left to right.

Online resources were offered as required and as recommended assignments and gave instant feedback on the accuracy of the solution, but did not provide feedback on specific errors committed. MEL allows assessment variations to be timed or untimed, with a single or multiple (3) attempts per question depending the assignment format chosen. Figure 2 shows an example using the MEL system, featuring a traditional textbook problem with instant feedback on the accuracy of the answer. 


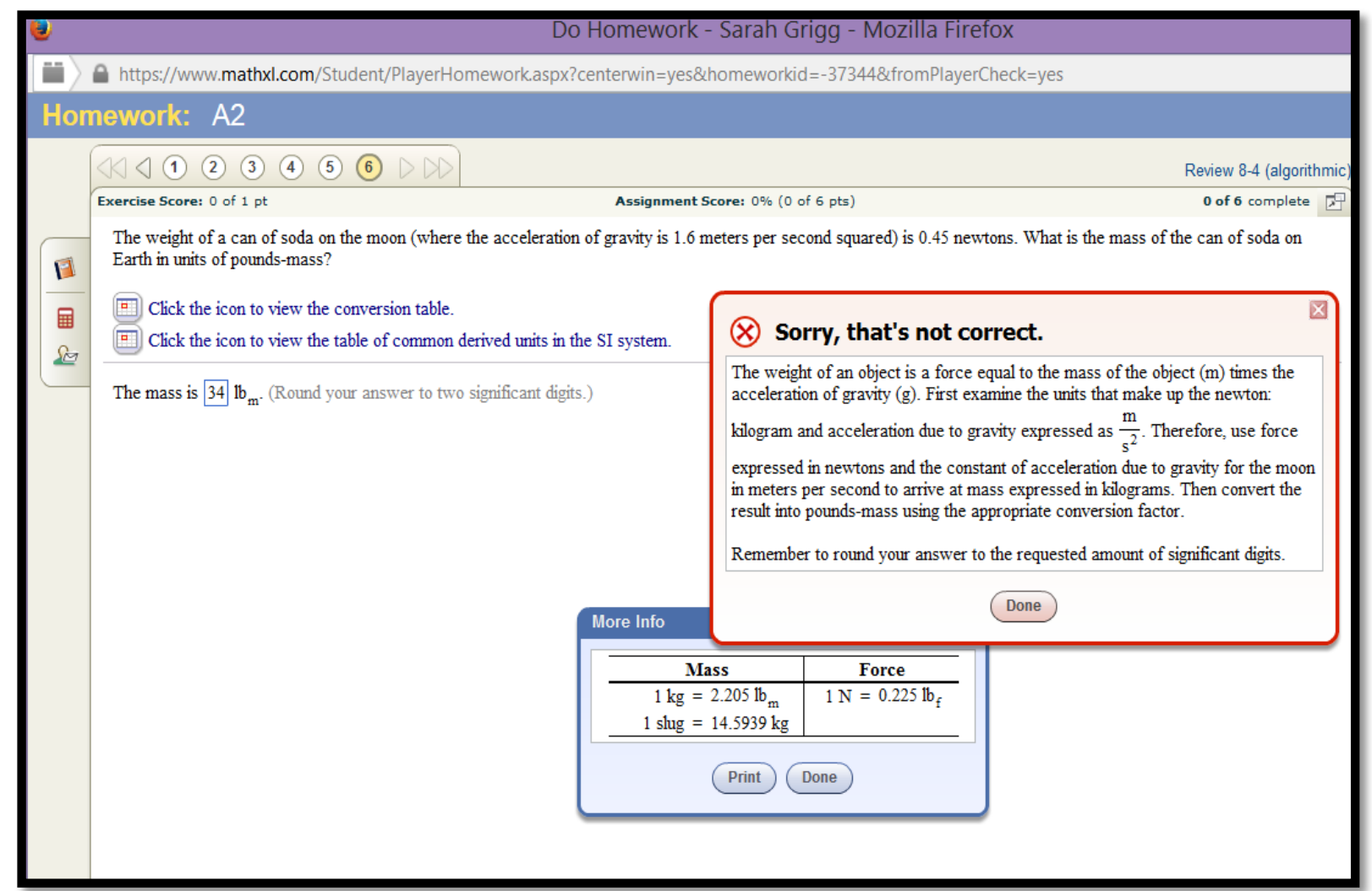

Figure 2: Example of the MEL online assignment management system providing instant feedback and multiple solution attempts for assigned and practice homework assignments.

The class met for 50 minutes, two days per week, for 7 weeks and the number of instances of utilizing each learning resource was directly proportional to the number of assignments. Table 1 summarizes the variations between the seven resources.

Table 1: Summary of learning resources and variations studied during Fall 2015 first-term course

\begin{tabular}{|l|c|c|c|c|c|}
\hline \multicolumn{1}{|c|}{ Learning Resource } & $\begin{array}{c}\text { Number } \\
\text { Instances }\end{array}$ & $\begin{array}{c}\text { Delivery } \\
\text { Method }\end{array}$ & $\begin{array}{c}\text { Social } \\
\text { Interaction }\end{array}$ & $\begin{array}{c}\text { Feedback } \\
\text { Timeliness }\end{array}$ & $\begin{array}{c}\text { Evaluation } \\
\text { Consequences }\end{array}$ \\
\hline $\begin{array}{l}\text { In-class module } \\
\text { worksheets }\end{array}$ & $\mathrm{n}=6$ & in-class & Individual & Instant & Not Graded \\
\hline Timed, in-class games & $\mathrm{n}=3$ & in-class & Team & Instant & Graded \\
\hline Hands-on labs & $\mathrm{n}=4$ & in-class & Team & Delayed & Graded \\
\hline $\begin{array}{l}\text { PROCESS feedback, } \\
\text { written problems }\end{array}$ & $\mathrm{n}=6$ & in-class & Individual & Delayed & Graded \\
\hline $\begin{array}{l}\text { Timed practice quizzes, } \\
\text { MEL }\end{array}$ & $\mathrm{n}=6$ & online & Individual & Instant & Not Graded \\
\hline $\begin{array}{l}\text { Untimed practice } \\
\text { assignments, MEL }\end{array}$ & $\mathrm{n}=10$ & online & Individual & Instant & Not Graded \\
\hline $\begin{array}{l}\text { Instant accuracy } \\
\text { feedback, MEL }\end{array}$ & $\mathrm{n}=10$ & online & Individual & Instant & Graded \\
\hline
\end{tabular}


At the end of the term, students and instructors were surveyed regarding their perceived effectiveness of the seven learning resources. Figure 3 depicts the survey items evaluated using a 5-point Likert scale, with 5 being very effective and 1 being ineffective. Survey data was collected from 12 of the 24 course sections (50\%). Surveys were completed by 342 out of 449 students in those sections (76\% of students within the 12 course sections; $26 \%$ of all students completing the course). Seven instructors took the survey.

Rate how effective the following learning tools were in improving your ability to solve engineering problems on a scale of $1-5$ with 1 strongly disagree and 5 being strongly agree.

\begin{tabular}{|c|c|c|c|c|c|c|}
\hline Hands-on learning such as the Energy Lab (bouncing balls) and Density Lab (material rods) & (:) & 1 & 2 & 3 & 4 & $5+$ \\
\hline Timed in class games such as scratch off cards and Jeopardy & (:) & 1 & 2 & 3 & 4 & $5+$ \\
\hline Timed practice quizzes on My Engineering Lab & 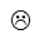 & 1 & 2 & 3 & 4 & $5+$ \\
\hline Untimed practice assignments on My Engineering Lab & $\bullet$ & 1 & 2 & 3 & 4 & $5+$ \\
\hline Instant feedback on My Engineering Lab assignments & (2) & 1 & 2 & 3 & 4 & $5+$ \\
\hline Timed practice quizzes on My Engineering Lab & (:) & 1 & 2 & 3 & 4 & $5 \div$ \\
\hline PROCESS feedback on hand written problem solving assignments & (:) & 1 & 2 & 3 & 4 & 5 (;) \\
\hline
\end{tabular}

Figure 3: Survey item on the effectiveness of various learning resources.

Students that completed the survey were used as the sample assessed in this paper. In order to ensure this group was representative, the distribution of final course grades were compared for the survey respondents to 1) all students who completed the course in one of the sections where the survey was distributed and 2) all students taking the class. The survey respondent group had a slightly higher response rate from students earning A or B grades and a slightly lower response rate from students earning $\mathrm{D}$ or $\mathrm{F}$ grades. As illustrated in Table 2, the groups appear to have similar final grade distributions. No other factors were evaluated to determine differences between groups.

Table 2: Distribution of students in the sample

\begin{tabular}{|c|c|c|c|c|c|c|c|}
\hline Grade & \multicolumn{2}{|c|}{$\begin{array}{c}\text { Survey } \\
\text { Respondents } \\
(\mathbf{n}=342)\end{array}$} & \multicolumn{2}{|c|}{$\begin{array}{c}\text { All students in } \\
\text { sections given the } \\
\text { survey (n=449) }\end{array}$} & \multicolumn{2}{|c|}{$\begin{array}{c}\text { All students in } \\
\text { the course } \\
\text { (n=1329) }\end{array}$} & $\begin{array}{c}\text { Percent } \\
\text { Difference }\end{array}$ \\
\hline A & 112 & $33 \%$ & 116 & $26 \%$ & 379 & $29 \%$ & $+4 \%$ \\
\hline B & 144 & $42 \%$ & 177 & $39 \%$ & 488 & $37 \%$ & $+5 \%$ \\
\hline C & 76 & $22 \%$ & 107 & $24 \%$ & 298 & $22 \%$ & $0 \%$ \\
\hline D & 7 & $2 \%$ & 31 & $7 \%$ & 87 & $7 \%$ & $-5 \%$ \\
\hline F & 3 & $1 \%$ & 18 & $4 \%$ & 77 & $6 \%$ & $-5 \%$ \\
\hline
\end{tabular}




\section{Results}

Of the seven learning resources included in the survey, only two received weighted scores greater than 4 on a 5-point scale for the student responses. Both resources involved the use of MyEngineeringLab (MEL). Students found the instant feedback on MEL assignments (4.6) and the untimed practice MEL assignments (4.2) were the most effective learning resources. Instructors disagreed, rating these resources at 3.3 and 3.0, respectively. Instructors rated the inclass learning resources as the most effective, including in-class games (3.9) and in-class module worksheets (3.9).

The data from student survey respondents was then analyzed in three groups: students earning a final course grade of A (A cohort), students earning a final course grade of B (B cohort), and students earning a final course grade of $\mathrm{C}$ (C cohort). Table 3 summarizes the variation found between each group of students. The A cohort rated all learning resources as less effective than the other students except for the instant feedback on MEL assignments, which the A cohort rated at 4.7 out of 5 . While the B and C cohorts also ranked the instant MEL feedback the highest, they ranked the untimed practice MEL assignments $(4.3,4.2)$ and then the in-class module worksheets $(4.0,3.8)$ as the next most effective learning resources. The $C$ cohort found the PROCESS feedback to be more effective than the other students.

Table 3: Summary of weighted scores of survey item responses grouped by performance level and role in the course

\begin{tabular}{|l|c|c|c|c|c|}
\hline \multirow{2}{*}{ Survey Items } & \multirow{2}{*}{ Faculty } & \multicolumn{5}{c|}{ Student Survey Respondents } \\
\cline { 3 - 6 } In-class module worksheets & $\mathbf{3 . 9}$ & 3.8 & 3.7 & $\mathbf{4 . 0}$ & $\mathbf{3 . 8}$ \\
\hline Timed, in-class games & $\mathbf{3 . 9}$ & 3.2 & 3.1 & 3.2 & 3.2 \\
\hline Hands-on labs & 3.6 & 3.3 & 3.1 & 3.4 & 3.4 \\
\hline $\begin{array}{l}\text { PROCESS feedback, written } \\
\text { problems }\end{array}$ & 3.4 & 3.5 & 3.3 & 3.5 & 3.7 \\
\hline $\begin{array}{l}\text { Timed practice quizzes, } \\
\text { MEL }\end{array}$ & 3.1 & 3.5 & 3.3 & 3.7 & 3.6 \\
\hline $\begin{array}{l}\text { Untimed practice } \\
\text { assignments, MEL }\end{array}$ & 3.0 & $\mathbf{4 . 2}$ & 3.5 & $\mathbf{4 . 3}$ & $\mathbf{4 . 2}$ \\
\hline $\begin{array}{l}\text { Instant accuracy feedback, } \\
\text { MEL }\end{array}$ & 3.3 & $\mathbf{4 . 6}$ & $\mathbf{4 . 7}$ & $\mathbf{4 . 6}$ & $\mathbf{4 . 5}$ \\
\hline
\end{tabular}

\section{Discussion}

At first glance, it appears students find the digital learning resources as most effective while instructors feel the in-class learning resources are most effective. However, under deeper thought about the characteristics of each learning tool, other plausible confounding factors were 
discovered. For example, the MEL system has several features that allow the instructor to limit either the time or the number of answer attempts. The untimed practice assignments presented a reduced pressure environment for students to practice problem solving with multiple chances to obtain the correct answer without negatively impacting the assignment grade. This reduced consequences option may seem favorable to students, as indicated by the preference of the B/C cohorts, but it is unclear if the students' rated untimed assignments as more effective due to the reduced stress atmosphere or if the rating is skewed by the grade consequences associated with other resources. Other factors that could explain the lower effectiveness ratings of in-class learning resources from students include the time spent for laboratory set-up and break-down during the hands-on modules and the anxiety associated with working in groups during in-class review games. Finally, it is possible some students interpreted the question differently than intended and may have answered based on how effective the resource was at obtaining correct answers to problems versus how effective the resource was at improving problem solving skills.

\section{Conclusions and Implications for Practice}

Promoting problem solving development is a major focus of our first year engineering course sequence. Determining how effective learning resources are in this development is key to ensure the best possible education for students. Future work will expand the survey to include questions on the different aspects of the learning resources beyond effectiveness, attempting to address ambiguity in student responses. Other forms of assessment will be included such as performance measures, though more work is required to ensure that assessment measures are equivalent in determining problem solving skill. Research is ongoing, and the instructors continue to explore different combinations of teaching and learning methods in an attempt to determine the most effective mixture of resources that appeal to the students.

\section{References}

1. Clemson Office of Institutional Research Fact Book. http://www.clemson.edu/oirweb1/DM/StudentMajorsEnrolled.cgi .

2. Jonassen D, Strobel J, Lee CB. Everyday problem solving in engineering: Lessons for engineering educators. J Eng Educ. 2006;95(2):139-151.

3. Foor CE, Walden SE, Trytten DA. "I wish that i belonged more in this whole engnieering group:" achieving individual diversity. J Eng Educ. 2007;96(2):103-115.

4. Oliver-Hoyo M, Beichner R. SCALE-UP: Bringing Inquiry-Guided Methods to Large Enrollment Courses. In: Lee VS, ed. Teaching and Learning Through Inquiry: A Guidebook For Institutions and Instructors. Sterling, Virginia: Stylus Publishing; 2004.

5. Prince M, Felder RM. Inductive teaching and learning methods: Definitions, comparisons, and research bases. J Eng Educ. 2006;95(2):123-138.

6. Benson LC, Orr MK, Biggers SB, Moss WF, Ohland MW, Schiff SD. Student-Centered Active, Cooperative Learning in Engineering. Int J Eng Educ. 2010;26(5):1097-1110. 
7. Beichner R, Saul J, Abbot D, et al. Student-Centered Activities for Large Enrollment Undergraduate Programs (SCALE-UP) project. In: Redish E, Cooney P, eds. Research-Based Reform of University Physics. College Park, MD: American Association of Physics Teachers.

8. Jonassen DH. Learning to Solve Problems. San Fransisco, CA: Pfeiffer; 2004.

9. Pearson Higher Education. http://www.pearsonmylabandmastering.com/northamerica/myengineeringlab/.

10. Grigg S, VanDyken J, Morkos B, Benson L. Process Analysis as a Feedback Tool for Development of Engineering Problem Solving Skills. In: ASEE Annual Conference. Atlanta, Ga; 2013. 